\title{
ENZYMATIC SYNTHESIS OF STRUCTURED LIPID BASED ON SILKWORM OIL AND PALM OLEIN
}

\author{
THUMU RAVINDER*; SHIVA SHANKER KAKI*; PRABHAKAR, I N S S*; RAO, B V S K *; \\ SARAT KUMAR SWAIN** and PRASAD, R B N*
}

\begin{abstract}
The present study describes the synthesis and characterisation of structured lipid (SL) containing $\alpha$-linolenic acid (ALA) prepared from palm olein (POo) and silkworm oils (SWO) employing enzymatic interesterification method. POo was chosen as one of the substrate because it does not contain ALA and is oxidatively more stable compared to other vegetable oils. The study was aimed to obtain an ALA content of about 10\% in the structured lipid which was achieved with the blend of POo and SWO in the ratio of 80:20 (wt/wt). The reactions were catalysed by a sn-1, 3-regiospecific lipase, Lipozyme RM IM. The effect of reaction time, temperature were studied and were found to be at $4 \mathrm{hr}$ and $65^{\circ} \mathrm{C}-70^{\circ} \mathrm{C}$ respectively at a lipase concentration $4 \%$ (w/w) of substrates. Physico-chemical characteristics of both the substrate oils were determined and compared with those of initial physical blends and the prepared SL. The oxidative stability of SL was also studied and the induction time was found to be at $13.2 \mathrm{hr}$ which was higher with respect to SWO. The SL prepared using refined POo, SWO has potential applications in nutraceutical, food and industrial applications.
\end{abstract}

Keywords: POo, eri SWO, a-linolenic acid, interesterification, structured lipid, physico-chemical characterisation.

Date received: 5 April 2016; Sent for revision: 5 August 2016; Received in final form: 7 November 2016; Accepted: 5 January 2017.

\section{INTRODUCTION}

Structured triacylglycerols with the desired fatty acids are the most effective designer lipids which can be used as nutraceuticals or functional foods to target specific diseases and metabolic conditions. A number of SL are known to have applications as reduced calorie fats, infant nutrition, medium chain triglycerides (MCT), polyunsaturated fatty acids (PUFA) and newer products are being developed with physiologically important fatty acids (Osborn, 2002; Sanjit, 2013; Marek, 2004). According to Kris

Centre for Lipid Research, CSIR-Indian Institute of Chemical Technology, Uppal Road, Tarnaka, Hyderabad-500 007, India. E-mail: rbnprasad@gmail.com

** Department of Chemistry, Veer Surendra Sai University of Technology, Burla, Sambalpur-768 018, India. et al., PUFA including $\alpha$-linolenic acid (ALA) are vital for maintaining biofunctions in mammalians and have important functions related to heart, circulation and inflammation (Kris, 2004). Studies showed that SL containing medium chain and n-3 fatty acid is highly desirable for the inhibitory effect on tumour growth and also showed good nitrogen balance in Yoshida sarcoma-bearing rats (Akoh, 1995). Among the several PUFA available, recent reports suggest that ALA is gaining importance as important nutraceutical agent in disease conditions associated with brain (Nicolas, 2015). Previous reports on ALA containing fat spreads were obtained from the blends of flaxseed and palm oil (EI-Waseif, 2013). Flaxseed oil was also used for the biosynthesis of structured lipids by interesterification with tricaprylin (Khodadadi, 2013). In one of the study, improved thermal properties were observed for 
the structured lipid prepared from palm stearin and linseed oil (Cecile, 2012). Linseed oil which contains a high amount of ALA was used for the preparation of SL with balanced omega-3 fatty acids with ground nut oil (Sharma, 2009). The SL enriched with n-3 PUFA (ALA) was used for the prevention of cholesterol and heart related diseases (Rupani, 2014). Reports are also available on the use of perilla oil which contains $63 \%$ ALA for interesterification with corn oil to produce ALA containing SL (Mitra, 2012). However, the SL prepared from POo or palm stearin blended with flaxseed oil was found to be a unique mixture having $n-3$ and n-6 fatty acids in considerable amounts (Long, 2003).

Among various oils, palm oil (PO) and its fractions are considered as potential substrates for lipid modification for edible purposes because of their high thermal, oxidative stability and plasticity. Literature studies also suggest that PO and its fractions have been widely employed for the preparation of SL (Kaki, 2012; Long, 2003; Cecile, 2012). As PO does not contain any ALA, it is a better substrate to be studied for incorporation of ALA.

In the present study, we have employed eri silkworm as a source of ALA for the preparation of SL. It was reported that eri silkworm oils contain a high amount of ALA in the range of 45\%-55\% depending on the feeding source (Kaki, 2006). The oil has been studied for its toxicity and was found that it is equivalent to other vegetable oils and also the oxidative stability of the SWO was shown to be improved when stored with appropriate antioxidants (Thumu, 2015; Longvah, 2012). As part of our research interest on value addition to eri silkworm oil (Ravinder, 2015; Kaki, 2014; Thumu, 2015), we attempted to prepare a SL with eri SWO and $\mathrm{PO}$ as substrates.

\section{MATERIALS AND METHODS}

\section{Materials}

Fatty acid mixtures (C4-24), reference triacylglycerols were purchased from Sigma Chemical Co., USA. Lipozyme TL IM [granulated silica preparation of a microbial lipase from Thermomyces lanuginosus with an activity of 75 IUN g-1 (IUN is Interesterification Unit Novo $\mathrm{g}^{-1}$ )] was a gift sample from M/s Novozymes South Asia Pvt Ltd, Bangalore, India. High performance liquid chromatography (HPLC) grade solvents were procured from M/s Merck, Mumbai, India. All chemicals and reagents used in the present work were of analytical reagent-grade and were purchased from SD Fine-Chemicals, Mumbai, India.

Refined POo sample was purchased from the local market, manufactured by $\mathrm{M} / \mathrm{s}$ Ushodaya Enterprises Pvt Ltd (Foods Division),
Kakinada, Andhra Pradesh, India. The silkworm pupae of tapioca leaf fed was collected from Rampachodavaram, E G District, Andhra Pradesh, India.

\section{Methods}

Extraction and refining of SWO. SWO was extracted from dried eri silkworm pupae according to a reported method (Kaki, 2006). The crude tapioca leaf fed SWO was refined by degumming, neutralisation, bleaching and deodorisation methods to remove impurities such as free fatty acid, phospholipids, dark colour pigments and odoriferous components (Ravinder, 2015).

Preparation of physical blend. Refined POo and refined SWO blend was prepared by taking in the ratio of 80:20 according to standard specifications and homogenised (PFA, 2005; BIS, 1995). The mixture of blend was heated under stirring for 30 min at $70^{\circ} \mathrm{C}$ under reduced pressure $(10 \mathrm{mmHg})$ for the preparation of physical blend (Kaki, 2012). The blend was prepared to get the ALA content around $10 \%$ in the sample.

Enzymatic interesterification of SWO and PO. Palm and SWO binary blend (100 g) was used as substrate for enzymatic interesterification using Lipozyme TL-IM (4\% wt/wt of total substrate) following a reported protocol (Kaki, 2012). The reaction mixture was magnetically stirred for $8 \mathrm{hr}$ at $65^{\circ} \mathrm{C}-70^{\circ} \mathrm{C}$. Aliquots were collected at $0,1,2,4$, 6 and $8 \mathrm{hr}$ time interval for HPLC analysis. Before sampling, stirring was stopped and the enzyme was allowed to settle at the bottom and sample was withdrawn from the top for further analysis. After 8 $\mathrm{hr}$, the product was separated from the enzyme and was stored in the refrigerator until further use. The product was analysed for fatty acid composition by gas chromatography (GC), molecular species by HPLC, oxidative stability by Rancimat assay and other physico-chemical parameters.

Physico-chemical characterisation. POo, SWO and their blends before, after interesterificaion were analysed for different physico-chemical characteristics like free fatty acids, iodine value, peroxide value, unsaponifiable matter, saponification value, $\mathrm{p}$-anisidine value, refractive index, cloud point and colour according to AOCS methods (AOCS, 2003). The phosphorous content determined followed by IUPAC method (IUPAC, 1987).

Total oxidation (TOTOX) value. TOTOX value measures the total oxidation, which includes primary and secondary oxidation products. These values reflect the initial and later stages of the oil 
oxidation. TOTOX values of the oil samples were determined based on the obtained peroxide value and $\mathrm{p}$-anisidine values. It was calculated according to a reported method (Shahidi, 2008) using Equation (1):

Total oxidation $($ TOTOX) value $=2 \times \mathrm{PV}+\mathrm{PAV}$ where PV - peroxide value, and PAV - p-anisidine.

Thiobarbituric acid-reactive substances (TBARS) test. TBARS measures the formation of secondary oxidation products, which are determined according to a reported method (Mariod, 2014). The oil samples (200 mg of each) were weighed into a $25 \mathrm{ml}$ volumetric flask separately. The samples were dissolved in 1-butanol and make up to the mark with butanol. The solution of $5 \mathrm{ml}$ portion was transferred into a dry test tube and a $5 \mathrm{ml}$ quantity of fresh thiobarbituric (TBA) reagent (200 mg TBA in $100 \mathrm{ml}$ 1-butanol) was added to it. Then, the test tube was kept at $95^{\circ} \mathrm{C}$ in a water bath and heated for about $120 \mathrm{~min}$. After that the tube was taken out and cooled to room temperature. The absorbance of the solution was measured at $532 \mathrm{~nm}$. The values obtained in the test are commonly described as TBARS (TBA reactive substances) and the TBARS value calculated as follows:

$$
\begin{aligned}
& \text { TBARS value }=\frac{(\mathrm{A} \times 0.415)}{\mathrm{m}} \\
& \begin{aligned}
\text { where } \quad \mathrm{A}-\text { absorbance at } 532 \mathrm{~nm} \text {, and } \\
\mathrm{m} \text { - mass of the sample }(\mathrm{g}) .
\end{aligned}
\end{aligned}
$$

Preparation of fatty acid methyl esters. POo, SWO and their blends before, after reaction were converted to fatty acid methyl esters (FAME) according to the method described by Christie (Christie, 1982). The oil (10-20 mg) was taken in $15 \mathrm{ml}$ of $2 \% \mathrm{H}_{2} \mathrm{SO}_{4}$ in methanol reagent and refluxed for about $4 \mathrm{hr}$. After complete conversion as confirmed by TLC, solvent was partially removed and the remaining mixture was extracted with ethyl acetate $(2 \times 20 \mathrm{ml})$, followed by water washings till neutral. Then the ethyl acetate extract was dried over anhydrous sodium sulphate and evaporated under reduced pressure on a rotary evaporator to obtain FAME.

GC analysis. The fatty acid methyl esters analysis of oils were performed on Agilent $6890 \mathrm{~N}$ Series Gas Chromatograph equipped with a FID and the capillary column DB- $225(30 \mathrm{~m} \times 0.25 \mathrm{~mm}$ i.d. $\times$ $0.5 \mu \mathrm{m}$ film thickness). The injector and detector temperatures were maintained at $230^{\circ} \mathrm{C}$ and $250^{\circ} \mathrm{C}$ respectively. The oven temperature was programmed for $2 \mathrm{~min}$ at $160^{\circ} \mathrm{C}$, further increased to $230^{\circ} \mathrm{C}$ at $5^{\circ} \mathrm{C} \mathrm{min}{ }^{-1}$ and finally maintained for 10 $\min$ at $230^{\circ} \mathrm{C}$. The carrier gas, nitrogen was used at a flow rate of $1.5 \mathrm{ml} \mathrm{min}^{-1}$. The injection volume was $1 \mu \mathrm{l}$, with a split ratio of 50:1.
Triacylglycerol (TAG) molecular species determination by HPLC. Triglyceride molecular species were determined by reversed phase HPLC equipped with a quaternary pump and an evaporative light scattering detector (ELSD 2000, Alltech, Deerfield, IL, USA). The drift tube temperature of the ELSD was set at $50^{\circ} \mathrm{C}$ and the nebulising gas (nitrogen) flow rate was set at 1.5 litre $\mathrm{min}^{-1}$. POo, SWO and structured lipid prepared from their physical blend were injected about 25 $\mu \mathrm{l}$ of $1 \mathrm{mg} \mathrm{ml}^{-1}$ concentration in to the reversed phase silica column (X Bridge TM C18, $5 \mu \mathrm{m}, 4.6 \mathrm{x}$ $250 \mathrm{~mm}$ ). The molecular species were eluted with mobile phase acetone $(100 \%)$ at a flow rate of $1 \mathrm{ml}$ $\mathrm{min}^{-1}$. The molecular species of oils and SL were tentatively identified by their equivalent carbon numbers (ECN) and with the elution order (Reena, 2009; Buchgraber, 2004).

Rancimat assay. The oxidative stability of individual oils and the interesterified products was evaluated by the Rancimat method (Trujillo, 2006). The test was performed on a Rancimat apparatus (Metrohm Co., Herisau, Switzerland). The Rancimat apparatus was operated at $110^{\circ} \mathrm{C}$ with a constant dry air flow (20 litres hr-1), which was blown through the sample $(5 \mathrm{~g})$. The volatile oxidation products which are produced during the oxidation of oils are causes to increase the conductivity of the water. The oxidative stability index (OSI) was obtained by induction periods (IP) which were calculated automatically by Rancimat method (Ley, 2003). When the conductivity of the distilled water is recorded continuously an oxidation curve is obtained whose point of inflection is known as the induction time expressed in hours. The high induction time indicates the increased of oxidative stability of the oils. All the analyses were performed in triplicate and the values given are average of the three measurements.

\section{RESULTS AND DISCUSSION}

The crude SWO was extracted from eri silkworm pupae and the oil was found to be $20.4 \%$ which was refined to remove undesirable components. Refined POo and refined SWO were analysed for different physico-chemical characteristics and the results are given in Table 1.

For the preparation of $\mathrm{SL}$, the ratio of $\mathrm{PO}$ and SWO blend was restricted to $80: 20(\mathrm{wt} / \mathrm{wt}$ ) based on the regulations of Prevention of Food Adulteration Act (PFA, 2005) and Bureau of Indian Standards methods (BIS, 1995). The interesterification reaction was initiated by the addition of lipase and the reported conditions were employed for the preparation of SL. The properties of initial oils, physical blend of palm and SWO along with SL were analysed for different physico-chemical characteristics and the results are shown in Table 1. 
TABLE 1. PHYSICO-CHEMICAL CHARACTERISTICS OF STRUCTURED LIPID AND SUBSTRATES

\begin{tabular}{|c|c|c|c|c|}
\hline Characteristic & SWO & PO & SWO:PO Blend & Structured Lipid \\
\hline FFA $(\%)$ & $0.17 \pm 0.01$ & $0.16 \pm 0.01$ & $0.16 \pm 0.01$ & $0.25 \pm 0.07$ \\
\hline Peroxide value & $2.81 \pm 0.22$ & $0.98 \pm 0.12$ & $1.38 \pm 0.12$ & $1.51 \pm 0.09$ \\
\hline Iodine value $\left(\mathrm{g} 100 \mathrm{~g}^{-1}\right)$ & $154.80 \pm 0.31$ & $58.72 \pm 0.11$ & $71.61 \pm 0.08$ & $72.81 \pm 0.15$ \\
\hline Unsaponifiable matter $(\%)$ & $2.18 \pm 0.17$ & $0.31 \pm 0.04$ & $0.49 \pm 0.09$ & $0.48 \pm 0.10$ \\
\hline Saponification value $\left(\mathrm{mg}\right.$ of $\left.\mathrm{KOH} \mathrm{g}^{-1}\right)$ & $195.32 \pm 0.10$ & $199.05 \pm 0.14$ & $198.22 \pm 0.14$ & $198.51 \pm 0.14$ \\
\hline Phosphorous (ppm) & 0 & 0 & 0 & 0 \\
\hline $\mathrm{p}$-anisidine value & $8.38 \pm 0.12$ & $4.25 \pm 0.07$ & $5.31 \pm 0.08$ & $5.40 \pm 0.09$ \\
\hline TOTOX value & $13.99 \pm 0.57$ & $6.20 \pm 0.31$ & $8.06 \pm 0.32$ & $8.74 \pm 0.27$ \\
\hline TBAR & $0.42 \pm 0.02$ & $0.39 \pm 0.01$ & $0.40 \pm 0.01$ & $0.40 \pm 0.02$ \\
\hline Colour in $1 "$ cell as $(Y+5 R)$ & $28(18 \mathrm{Y}, 2 \mathrm{R})$ & $14(7 \mathrm{Y}, 1.4 \mathrm{R})$ & 20 (15Y, 1R) & $18(12 \mathrm{Y}, 1.2 \mathrm{R})$ \\
\hline Refractive index $\left(40^{\circ} \mathrm{C}\right)$ & 1.4697 & 1.4691 & 1.4612 & 1.4613 \\
\hline Cloud point $\left({ }^{\circ} \mathrm{C}\right)$ & 3 & 14.5 & 14.0 & 23.0 \\
\hline
\end{tabular}

Note: SWO - silkworm oils.

PO - palm oil.

FFA - free fatty acid.

TOTOX - total oxidation

TBAR - tribarbituric acid-refractive.

The results showed that, the iodine value (154.8) was much higher in SWO than the PO (58.72) which is due to the presence of linolenic acid in higher quantity in silkworm oil. Peroxide value was also observed to be slightly higher in SWO (2.81) compared to PO (0.98). Phospholipids were not present in both the oils, which were removed completely during refining. Saponification value of PO (199.05) is slightly higher compared to SWO (195.32). The colour of the SWO was observed to be higher compared to PO. The p-anisidine value, TOTOX and TBAR values were observed to be higher in SWO compared to PO.

In the blend, the peroxide value was observed to be more than 1.38 compared to PO which had a peroxide value of 0.98 . The iodine value was increased from 58.72 to 71.61 compared to the initial palm oil. This increase in peroxide value and iodine value is due to the increase in unsaturated fatty acids which are present in SWO. A slight increase in $p$-anisidine value, TOTOX and TBAR values are observed in the physical blend compared to PO. The results also showed that there was no significant difference in the physico-chemical characteristics of the prepared SL and physical blend of palm and
SWO. However, there was considerable difference in the cloud point of the prepared SL compared to the blend. This shows that the interesterification resulted in increase in the cloud point which could be due to the exchange of acyl groups on the triglyceride back bone. The fatty acid composition of the structured lipid prepared from palm and SWO is given in Table 2 along with the initial oils and the physical blend.

The results showed that, the ALA content in SWO was observed to be $52.23 \%$, which is similar to flaxseed oil composition (Fazary, 2015). However, the content of linoleic acid $(18: 2, n-6)$ is higher in PO $(10.17 \%)$ compared to SWO $(4.18 \%)$. Similarly oleic and palmitic acids are higher in PO compared to SWO. Over all, saturated fatty acids were observed to be more in $\mathrm{PO}$ and unsaturated fatty acids were found to be more in SWO. ALA content was present at $9.23 \%$ in the blend of palm and SWO. Linoleic acid (18:2) was reduced from $10.17 \%$ to $8.82 \%$ in the blend compared to PO. The reduction in palmitic acid was also observed from $41.36 \%$ to $38.19 \%$ in the physical blend compared to PO. The same trend was observed in case of oleic acid, which was reduced from $44.69 \%$ to $38.23 \%$ in physical blend. The trans

TABLE 2. FATTY ACID (\%) COMPOSITION OF STRUCTURED LIPID AND SUBSTRATES

\begin{tabular}{lcccc}
\hline Fatty acid & Silkworm oil (SWO) & Palm oil (PO) & SWO:PO blend & Structured lipid \\
\hline Myristic acid (14:0) & $0.25 \pm 0.08$ & $0.69 \pm 0.06$ & $0.66 \pm 0.15$ & $0.78 \pm 0.12$ \\
Palmitic acid (16:0) & $24.71 \pm 0.04$ & $41.36 \pm 0.16$ & $38.19 \pm 0.58$ & $38.04 \pm 0.21$ \\
Palmitoleic acid (16:1) & $1.14 \pm 0.17$ & - & $0.16 \pm 0.03$ & $0.24 \pm 0.01$ \\
Stearic acid (18:0) & $3.93 \pm 0.03$ & $3.09 \pm 0.04$ & $4.69 \pm 0.75$ & $4.34 \pm 0.17$ \\
Oleic acid (18:1) & $13.54 \pm 0.32$ & $44.69 \pm 0.18$ & $38.23 \pm 0.46$ & $38.31 \pm 0.05$ \\
Linoleic acid (18:2) & $4.18 \pm 0.06$ & $10.17 \pm 0.11$ & $8.82 \pm 0.09$ & $8.88 \pm 0.18$ \\
Linolenic acid (18:3) & $52.23 \pm 0.19$ & - & $9.23 \pm 0.09$ & $9.38 \pm 0.14$ \\
\hline
\end{tabular}


fatty acid content in the SL was also determined and it was found that no trans fatty acid content was observed as lipase was used for interesterification reaction.

The molecular species of TAG of both the oils before and after interesterification were determined by using reversed phase HPLC and the results are shown in Table 3. The analysis indicated the formation of newer molecular species in modified lipid which were not present in the physical blend. The data indicated that the molecular species in SWO and SL were in the range of ECN C36-C48, where as in PO it was observed from $\mathrm{C} 42-\mathrm{C} 48$. The molecular species of SL was observed to possess C48 as the major component, followed by $\mathrm{C} 46$ and other species. The formation of new molecular species indicates that the enzymatic reaction was successful in exchange of fatty acids as reported by many studies in the literature (Kaki, 2012).

The prepared SL was further studied for OSI and was compared with substrate oils along with physical blend. The results are shown in Figure 1.

The rancimat assay results showed that the PO has higher oxidative stability $(17.67 \mathrm{hr})$ compared to SWO (3.86 hr). The large difference observed in oxidative stability for both palm and SWO is due to the variation in fatty acid composition particularly unsaturated fatty acids. The oxidative stability of the blend and interesterified SL is almost similar. After blending the palm and SWO at 80:20 ratios (wt/wt), a better oxidative stability was observed which is imparted by the saturated fatty acids from palm oil. In a reported study, the SL having 32.39\% of ALA prepared from perilla and corn oil was also shown to have higher oxidative stability compared to perilla oil due to the balanced saturated and unsaturated fatty acids (Mitra, 2014). The SL obtained after interesterificaion of palm and SWO at 80:20 ratios $(w t / w t)$ can be claimed as novel SL with better oxidative stability with potential value addition to both substrate oils. Further, the oxidative stability of the SL can be improved if a suitable antioxidant is added (Thumu, 2015). The SL prepared contains ALA in similar amounts to soyabean oil and hence, can be tested for the applications where soyabean oil is used to further expand its application. Further studies for producing additional SL with SWO could be of interest based on preliminary evaluation of the SL as SWO is reported to be safe based on its toxicological evaluation (Longvah, 2012).

TABLE 3. TRIACYGLYCEROL (TAG) MOLECULAR SPECIES OF OILS AND PHYSICAL BLEND

\begin{tabular}{lcccc}
\hline Effective carbon No. & Expected mol. species & Palm olein & Silkworm oil & Structured lipid \\
\hline C36 & LnLnLn & - & $16.71 \pm 0.20$ & $2.31 \pm 0.38$ \\
C38 & LLnLn & - & $5.77 \pm 0.15$ & $2.83 \pm 0.14$ \\
C40 & PLnLn/LLLn/OLnLn & - & $39.24 \pm 0.32$ & $3.11 \pm 0.79$ \\
C42 & LLL/PLLn/SLnLn/LLnO & $2.59 \pm 0.49$ & $7.96 \pm 0.56$ & $1.95 \pm 0.21$ \\
C44 & OOLn/LLO/PLL/PLnP/SLLn & $9.63 \pm 0.11$ & $22.08 \pm 0.61$ & $7.92 \pm 0.48$ \\
C46 & POL/OOL/PLP & $11.55 \pm 0.35$ & $2.64 \pm 0.04$ & $11.71 \pm 0.16$ \\
C48 & OOO/POP/SLnS & $76.22 \pm 0.53$ & $5.59 \pm 0.03$ & $70.16 \pm 1.08$ \\
\hline
\end{tabular}

Note: P - palmitic acid, S - stearic acid, O - oleic acid, L - linoleic acid, Ln - linolenic acid.

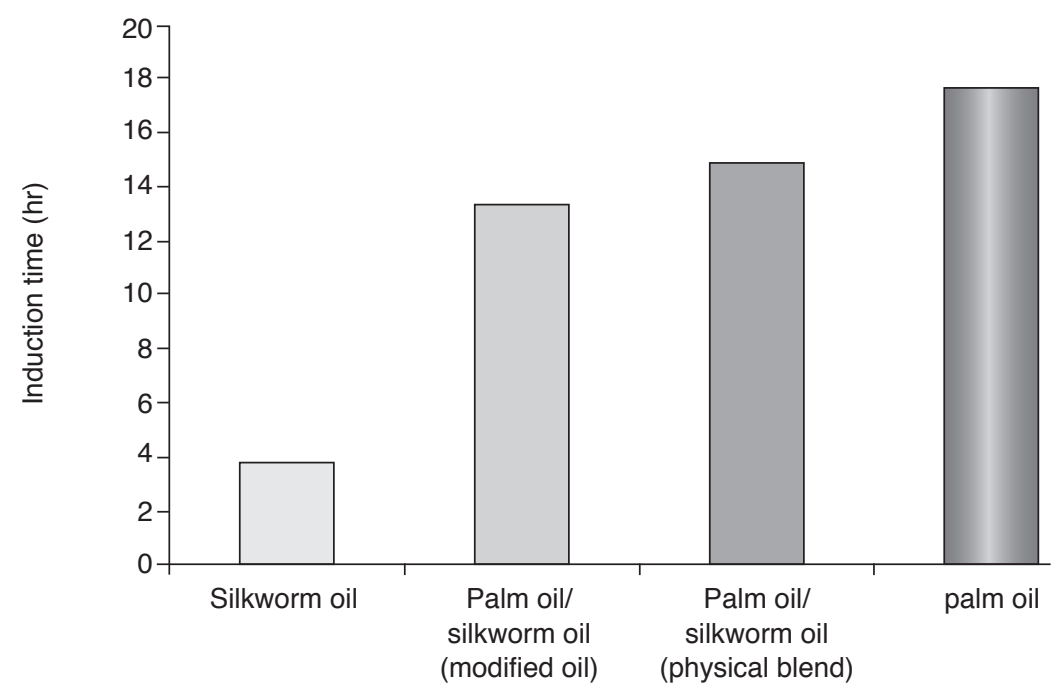

Figure 1. Oxidative stability of oils and modified oils. 


\section{CONCLUSION}

SL based on palm and SWO was designed and synthesised in this study. Physico-chemical characteristics of both the refined palm olein, silkworm oils were determined and compared with before and after interesterification. Refined PO and refined SWO were subjected to enzymatic interesterification to obtain SL with about $10 \%$ of ALA. The SL exhibited good oxidative stability compared to SWO. The SL prepared by the interesterification of refined $\mathrm{PO}$ and SWO has potential applications in nutraceutical, food and industrial applications.

\section{REFERENCES}

AKOH, C (1995). Structured lipids-enzymatic approach. Inform, 6:1055-1056.

AOCS (2003). Methods Ca 5a-40; Cd 1-25; Cd 8-53; Ca 6a-40; Cd 3-25; Cd 18-90; Cc 13e-92. Official Methods and Recommended Practices. $5^{\text {th }}$ Edition. AOCS Press, Champaign.

BUCHGRABER, M; ULBERTH, F; EMONS, $\mathrm{H}$ and ANKLAM, E (2004). Triacylglycerol profiling by using chromatographic techniques. European J. Lipid Science and Technology, 106: 621-648.

BIS (1995). Blended edible oil specifications; IS 14309. Bureau of Indian Standards Methods.

CHRISTIE, W W (1982). The preparation of derivatives of lipids. Lipid Analysis. $2^{\text {nd }}$ Edition, Pergamon Press Ltd, Oxford, UK. p. 52-54.

CECILE, C; NOWAKOWSKA, $M$ and ROUX, G A $C$ (2012). Thermal properties of the product of palm stearin and linseed oil transesterification. J. Chemical Engineering, 6: 971-978.

EL-WASEIF, M A; HASHEM, H A; ABD, $\mathrm{H} \mathrm{H}$ and DAYEM, E L (2013). Using flaxseed oil to prepare therapeutical fat spreads. Annals of Agricultural Science, 58(1): 5-11.

FAZARY, N T A A and YOUNIS, Y M (2015). Seed properties and fatty acid composition of flaxseed oil (Linum usitatissimum). World J. Pharmacy and Pharmaceutical Sciences, 4 (11).

IUPAC (1987). Standard Methods for the Analysis of Oils, Fats and Derivatives. $7^{\text {th }}$ Edition, Blackwell Publications. Oxford, UK. p. 183-184.

KRIS-ETHERTON, $\mathrm{P} \mathrm{M}$; HECKER, $\mathrm{K} \mathrm{D}$ and BINKOSKI, A E (2004). Poly-unsaturated fatty acids and cardiovascular health. Nutrition Reviews, 62: 414-426.

KHODADADI, M; SARYA, A; RICHARD, STLOUIS and SELIM, K (2013). Lipase-catalyzed synthesis and characterization of flaxseed oil-based structured lipids. J. Functional Foods, 5 (1): 424-433.

KAKI, S S; REDDY, K K; SANJIT, K and PRASAD, R B N (2012). Enzymatic preparation and characterization of trans-free fat from palm stearin and natural vegetable oils. J. Lipid Science \& Technology, 44 (3): 79-85.

KAKI, S S; SHIREESHA, K; KANJILAL, S; KUMAR, S V L N; SRINIVAS, C; RAO, J V K and PRASAD, R $B N$ (2006). Isolation and characterization of neutral lipids of desilked eri silkworm pupae grown on castor and tapioca leaves, J. Agricultural and Food Chemistry, 54: 3305-3309.

KAKI, S S; RAVINDER, T; ASHWINI, B; RAO, B V S K and PRASAD, R B N (2014). Enzymatic modification of phosphatidylcholine with n-3 PUFA from silkworm oil fatty acids. Grasas Y Aceites, 65 (2): e021. ISSN-L: 0017-3495.

LEY, J P and BERTRAM, H J (2003). 3,4-Dihydroxymandelic acid amides of alkylamines as antioxidants for lipids. European J. Lipid Science and Technology, 105: 529-535.

LONG, K; ZUBIR, I; HUSSIN, A.B; IDRIS, N; GHAZALI, H M and LAI, O M (2003). Effect of enzymatic transesterification with flaxseed oil on the high-melting glycerides of palm stearin and palm olein. J. Amer. Oil Chem. Soc., 80 (2): 133-137.

LONGVAH, T; MANGHTYA, K and QADRI, S S Y H (2012). Eri silkworm: a source of edible oil with a high content of $\alpha$-linolenic acid and of significant nutritional value. J. Science of Food and Agriculture, 92: 1988-1993.

MITRA, K; SHIN, J A; LEE, J H; KIM, S A; HONG, S T; SUNG, C K; XUE, C L and LEE, K T (2012). Studies of reaction variables for lipase-catalyzed production of alpha-linolenic acid enriched structured lipid and oxidative stability with antioxidants. J. Food Science, 71 (1).

MARIOD, A; ISMAIL, M; RAHMAN, N F and MATTHAUS, B (2014). Stability of rice bran oil extracted by SFE and soxhlet methods during accelerated shelf-life storage. Grasas Y Aceites, 65 (1): e013.

MITRA, K and KIM, S A (2014). Optimization the production of alpha linolenic acid enriched 
structural lipid and evaluation of the oxidative stability under accelerated storage conditions. Discourse J. Agriculture and Food Sciences, 2(7): 225234.

MAREK, A (2004). The aplication of lipases in modifying the composition, structure and properties of lipids. A review. Polish J. Food and Nutrition Sciences, 13/54 (1): 3-10.

NICOLAS, B (2015). The nutraceutical potential of omega-3 alpha-linolenic acid in reducing the consequences of stroke. Biochimie, 120: 49-55.

OSBORN, H T and AKOH, C C (2002). Structured lipids-novel fats with medical, nutraceutical, and food applications. Comprehensive Reviews in Food Science and Food Safety, 3: 110-120.

PFA (2005). Prevention of Food Adulteration Act (11 th Amendment) Rules, 2005. Ministry of Health and Family Welfare, Department of Health, G S R 596€, $4^{\text {th }}$ Amendment-1992. p. 1-13.

REENA, MB; REDDY, S R Y and LOKESH, B R (2009). Changes in triacylglycerol molecular species and thermal properties of blended and interesterified mixtures of coconut oil or palm oil with rice bran oil or sesame oil. European J. Lipid Science and Technology, 111: 346-357.

RAVINDER, T; KAKI, S S; SANJIT, K; RAO, B V S K; SWAIN, S K and PRASAD, R B N (2015). Refining of castor and tapioca leaf fed eri silkworm oils. International J. Chemical Science and Technology, 5(2): 32-37.

RUPANI, B; RAMCHANDRA, G; KISAN, K and GHASEM, D N (2014). Enrichment of olive oil with alpha linolenic acid catalyzed by lipase mediated trans-esterification. Iranica J. Energy $\mathcal{E}$ Environment, 5 (1): 18-25.

SANJIT, K; KAKI,S S; RAO, B V S K; SUGASINI, D; RAO, Y P; PRASAD, R B N and LOKESH, B R (2013). Hypocholesterolemic effects of low calorie structured lipids on rats and rabbits fed on normal and atherogenic diet. Food Chemistry, 136 (1): 259265.

SHARMA, M; NAVIN, K R and LOKESH, B R (2009). Synthesis of structured lipid with balanced omega-3: omega-6 ratio by lipase-catalyzed acidolysis reaction: optimization of reaction using response surface methodology. Process Biochemistry, 44 (11): 1284-1288.

SHAHIDI, F and WANASUNDARA, U N (2008). Methods for measuring oxidative stability in edible oils. Food Lipids: Chemistry, Nutrition and Biotechnology (Akoh, C C and Min, D B eds.). CRC Press, New York. p. 387-388.

Thumu Ravinder; Kaki, S S; PRABHAKAR, I N S S; RAO, B V S K; SWAIN, S K and PRASAD, R B N (2015). Effect of natural and synthetic antioxidants on oxidation of eri silkworm oils. Indo American J. Pharmaceutical Research, 5 (11): 3666-3675.

TRUJILLO, M; MATEOS, R; COLLANTES, T L; ESPARTERO, J L; CERT, R; JOVER, M; ALCUDIA, F; BAUTISTA, J; CERT, A and PARRADO, J (2006). Lipophilic hydroxytyrosyl esters. Antioxidant activity in lipid matrices and biological systems. J. Agricultural and Food Chemistry, 54 (11): 3779-3785. 